Pacific Journal of Mathematics

A MONOTONICITY PRINCIPLE FOR EIGENVALUES 


\title{
A MONOTONICITY PRINCIPLE FOR EIGENVALUES
}

\author{
V. B. HeAdLEY
}

The smallest eigenvalue of certain boundary problems for second order linear elliptic partial differential equations increases to infinity as the domain in question shrinks to the empty set. The object of this note is to formulate and prove an analogous result for linear elliptic differential operators $L$ of general even order. Specifically, let $G(t)$ be a bounded domain in $n$-dimensional Euclidean space, and suppose that $G(t)$ has thickness $t$ (in a sense which will be precisely defined below). Let $\lambda_{0}(t)$ be the smallest eigenvalue of a boundary problem associated with $L$ and $G(t)$. It will be shown that $\lambda_{0}(t)$ increases to infinity as $t$ tends to zero from the right.

The proof depends on a generalization of Agmon's form [1] of Poincaré's inequality. In the second-order case, a monotonicity principle of the type under consideration has been applied to obtain oscillation theorems (cf. [3], [4]) for partial differential equations on unbounded domains.

2. Preliminary lemmas. Let $G$ be a domain (not necessarily bounded) in $n$-dimensional Euclidean space $R^{n}$. We shall say that $G$ has bounded thickness $\leqq s$, or simply thickness $\leqq s$, if and only if there is a line $\ell$ such that each line parallel to $\ell$ intersects $G$ in a set each of whose components (i.e., maximal connected subsets) has diameter $\leqq s$. For example, if $|x|$ denotes the length $\left(\sum x_{i}^{2}\right)^{1 / 2}$ of the vector $x=\left(x_{1}, \cdots, x_{n}\right)$ in $R^{n}$, then the annulus $\left\{x \in R^{n}: r_{0}<|x|<r_{1}\right\}$, $r_{0}>0$, has thickness $\leqq 2 \sqrt[V]{ }\left[r_{1}^{2}-r_{0}^{2}\right]$.

Let $C^{m}(G)$ denote the class of all $m$ times continuously differentiable real-valued functions on $G$, and $C_{0}^{m}(G)$ denote the class of all $C^{m}$ functions having compact support in $G$. We use the standard multiindex notation: let $\alpha=\left(\alpha_{1} \cdots, \alpha_{n}\right)$ have nonnegative integral components and "norm" $|\alpha|=\alpha_{1}+\cdots+\alpha_{n}$; let $D_{i}^{\alpha_{i}}$ denote the partial differential operator $\left(\partial^{\alpha_{i}} / \partial x_{i}{ }^{\alpha_{2}}\right)$, and let $D^{\alpha}=D_{1}^{\alpha_{1}} \cdots D_{n}^{\alpha_{n}}$.

Lemma 1. If $G$ has bounded thickness $\leqq s$ and if every line parallel to the line $\ell$ in the definition of bounded thickness intersects $G$ in a set with at most $k$ components, where $k$ is some positive integer, then

$$
|v|_{j, G} \leqq(k s)^{m-j}|v|_{m, G}
$$

for all $v \in C_{0}^{m_{0}}(G), 0 \leqq j \leqq m-1$, where 


$$
|v|_{j, G}=\left.\left.\left|\int_{G} \sum_{|\alpha|=j}\right| D^{\alpha} v\right|^{2} d x\right|^{1 / 2} .
$$

Proof. We refine the argument given in [1, pp. 74-75]. Let $\ell^{\prime}$ be a line parallel to $\ell$, and assume that $x^{0}$ and $x^{0}+q$ are points in $\ell^{\prime} \cap \partial G$ such that $\ell^{\prime} \cap G$ is contained in the segment between $x^{0}$ and $x^{0}+q$. By defining $v$ to vanish outside $G$, we can assume that $v \in C_{0}^{m}\left(R^{n}\right)$. For $-\infty<t<+\infty$ let $f(t)=v\left(x^{0}+t|q|^{-1} q\right)$. Then $f(0)=$ 0 , so that

$$
f(t)=\int_{0}^{t} f^{\prime}(r) d r
$$

Since $v$ vanishes outside $G$,

$$
f(t)=\int_{K(G, t)} f^{\prime}(r) d r,
$$

where

$$
K(G, t)=\left\{r: r \leqq t \text { and } x^{0}+r|q|^{-1} q \in \ell^{\prime} \cap G\right\} .
$$

This set is by hypothesis a union of at most $k$ disjoint intervals, the sum of whose lengths is at most $k s$. By Schwarz's inequality,

$$
|f(t)|^{2} \leqq k s \int_{K(G, t)}\left|f^{\prime}(r)\right|^{2} d r \leqq k s \int_{-\infty}^{\infty}\left|f^{\prime}(r)\right|^{2} d r .
$$

Hence

$$
\begin{aligned}
\int_{-\infty}^{\infty}|f(t)|^{2} d t & =\int_{K(G,|q|)}|f(t)|^{2} d t \\
& \leqq(k s)^{2} \int_{-\infty}^{\infty}\left|f^{\prime}(r)\right|^{2} d r .
\end{aligned}
$$

Now express $|v|_{0, G}^{2}$ as an iterated integral with one of the integrations taken in the direction of $\ell$. From the last inequality above it follows that

$$
|v|_{0, G}^{2} \leqq(k s)^{2}|v|_{1, G}^{2}
$$

Applying this inequality to $D_{i} v$, we obtain

$$
\left|D_{i} v\right|_{0, G}^{2} \leqq(k s)^{2}\left|D_{i} v\right|_{1, G}^{2} \cdot
$$

Summing over all $i$, we obtain

$$
|v|_{1, G}^{2} \leqq(k s)^{2}|v|_{2, G}^{2} \cdot
$$

The conclusion of the lemma now follows by induction.

In the application mentioned in the introduction, if $G$ is an annulus 
with $r_{1}-r_{0}=t$, it is important to have an inequality of the form

$$
|v|_{0, G} \leqq g(t)|v|_{m, G},
$$

where the function $g$ is monotone strictly increasing. Such an inequality follows immediately from Lemma 1, but does not appear to be readily obtainable from the corresponding result in [1].

We now consider the $2 m$-th order linear elliptic partial differential operator $L$ defined by

$$
L u=(-1)^{m} \sum_{|\alpha|=|\beta|=m} D^{\alpha}\left(A_{\alpha \beta} D^{\beta} u\right)+B u,
$$

where $m$ is a positive integer, and $\alpha=\left(\alpha_{1}, \cdots, \alpha_{n}\right), \beta=\left(\beta_{1}, \cdots, \beta_{n}\right)$ are multi-indices with nonnegative integral components. The coefficients $A_{\alpha \beta}$ are supposed to be real-valued, symmetric in the indices, and have bounded continuous derivatives of all orders $\leqq m$ on $G$. The coefficient $B$ is real-valued, bounded, and continuous on $G$. For each $z \in R^{n}$ we write $z^{\alpha}=\prod_{i=1}^{n} z_{i}^{\alpha}{ }^{i}$.

Let $p(m)$ denote the number of distinct multi-indices $\alpha$ satisfying $|\alpha|=m$. For operators of the kind defined by (2), we shall suppose that there exists a number $E>0$ such that for all $x \in G$ and all $p(m)$-tuples $\left\{\xi_{\alpha}:|\alpha|=m\right\}$ of real numbers $\xi_{\alpha}$

$$
\sum_{|\alpha|=|\beta|=m} A_{\alpha \beta}(x) \xi_{\alpha} \xi_{\beta} \geqq E \sum_{|\alpha|=m} \xi_{\alpha}^{2} \text {. }
$$

Without loss of generality we assume that we may take $\xi_{\alpha}=\xi_{\gamma}$ if $\gamma=\left(\gamma_{1}, \cdots, \gamma_{n}\right)$ is a permutation of $\alpha=\left(\alpha_{1}, \cdots, \alpha_{n}\right)$. We note that the usual ellipticity condition is

(a) The form $\sum_{|\alpha|=|\beta|=m} A_{\alpha \beta}(x) z^{\alpha+\beta}$ is positive definite at each point $x \in G$.

If the coefficients $A_{\alpha \beta}$ are constant or if $L u$ has the form

$$
(-1)^{m} \sum_{i, j=1}^{n} D_{i}^{m}\left(a_{i j} D_{j}^{m} u\right)+B u,
$$

it can be shown that (3) is a consequence of the ellipticity condition (a). We now define the quadratic functional

$$
J[u]=\int_{G|\alpha|=|\beta|=m}\left(A_{\alpha \beta} D^{\alpha} u D^{\beta} u+B u^{2}\right) d x
$$

for $u \in C_{0}^{m}(G)$. Then the following special case of Gording's inequality is valid.

Lemma 2. Let $A_{\alpha \beta}$ satisfy (3). Then there exists a number $b>-\infty$ such that 


$$
J[u] \geqq E|u|_{m, G}^{2}+b|u|_{0, G}^{2}
$$

for all $u \in C_{0}^{m}(G)$.

Proof. Since $B$ is bounded and continuous on $G$, there exists a number $b>-\infty$ such that

$$
\int_{G} B u^{2} d x \geqq b \int_{G} u^{2} d x
$$

for all $u \in C_{0}^{m}(G)$. Condition (3) yields

$$
\int_{G|\alpha|=|\beta|=m} A_{\alpha \beta} D^{\alpha} u D^{\beta} u d x \geqq E \int_{G|\alpha|=m}\left(D^{\alpha} u\right)^{2} d x .
$$

Combining this with inequality (5) we obtain (4), and the lemma is proved.

Our next preliminary result is a form of Courant's variational principle [2].

LEMMA 3. Let $G$ be a bounded domain, with boundary $\partial G$ having a piecewise continuous unit normal. The function $u_{0} \in C^{2 m}(G)$ which minimizes the functional $J[u]$ under the condition $|u|_{0, G}=1$ is an eigenfunction corresponding to the smallest eigenvalue of the problem

$$
L u=\lambda u \text { in } G, D^{\alpha} u=0 \text { on } \partial G, 0 \leqq|\alpha| \leqq m-1 .
$$

Proof. According to $[5, \S \S 11,28]$, there exists a minimizing function $u_{0}$ which is a weak solution of (6) in the following sense:

$$
\left\langle u_{0},\left(L-\lambda_{0}\right) v\right\rangle=0, \quad v \in C_{0}^{\infty}(G),
$$

where $\langle$,$\rangle is the usual L^{2}[G]$ inner product and $\lambda_{0}$ is the minimum value of $J[u]$. The results of $[1, \S \S 8,9]$ now imply that $u_{0} \in C^{2 m}(G)$ and $u_{0}$ satisfies $L u=\lambda_{0} u$. A standard argument [2, p. 400] now shows that $\lambda_{0}$ is the smallest eigenvalue of (6).

3. The main result. For $0<t<\infty$ let $G_{t}$ be a bounded domain having a piecewise smooth boundary $\partial G_{t}$. We suppose that $G_{t}$ has thickness $\leqq t$, and that the line $\ell$ in the definition of bounded thickness intersects $G_{t}$ in a set with at most $k$ components. We suppose that $A_{\alpha \beta} \in C^{m}\left(\bar{G}_{t}\right)$ and that $B$ is continuous on $\bar{G}_{t}$. We also suppose that the coefficients $A_{\alpha \beta}$ satisfy condition (3) on $G_{t}$.

TheOREM. If $0<r<s<\infty$ implies that $G_{r}$ is a proper subset of $G_{s}$, then the smallest eigenvalue $\lambda_{0}(t)$ of the boundary problem 


$$
L u=\lambda u \text { in } G_{t} ; D^{\alpha} u=0 \text { on } \partial G_{t}, 0 \leqq|\alpha| \leqq m-1
$$

is monotone nonincreasing in $t$, and $\lim _{t \rightarrow 0+} \lambda_{0}(t)=+\infty$.

Proof. Introduce the notation

$$
J_{t}[u]=\int_{G_{t}} \sum_{|\alpha|=|\rho|=m}\left(A_{\alpha \beta} D^{\alpha} u D^{\beta} u+B u^{2}\right) d x,
$$

and

$$
\|u\|_{t}=|u|_{0, G_{t}},|u|_{m, t}=|u|_{m, G_{t}} .
$$

By Lemma 3,

$$
\lambda_{0}(t)=\inf \left\{J_{t}[u] /\|u\|_{t}^{2}: u \in C^{2 m}\left(G_{t}\right)\right\} .
$$

Since $G_{t}$ increases with $t$, it is clear that the class of admissible functions is nondecreasing, and therefore $\lambda_{0}(t)$ is nonincreasing in $t$. By Lemma 2, there exist numbers $E(t)>0, b(t)>-\infty$ such that

$$
J_{t}[u] \geqq E(t)|u|_{m, t}^{2}+b(t)\|u\|_{t}^{2} .
$$

According to Lemma 1,

$$
\|u\|_{t}^{2} \leqq(k t)^{2 m}|u|_{m, t}^{2} .
$$

Combining this with inequality (7) we obtain

$$
J_{t}[u] \geqq\left[(k t)^{-2 m} E(t)+b(t)\right]\|u\|_{t}^{2} .
$$

Hence

$$
\lambda_{0}(t) \geqq(k t)^{-2 m} E(t)+b(t) .
$$

Since $E(t)$ may be chosen to be the infimum of

$$
\left(\sum_{|\alpha|=|\beta|=m} A_{\alpha \hat{\beta}}(x) \xi_{\alpha} \xi_{\beta}\right) /\left(\sum_{|\alpha|=m} \xi_{\alpha}^{2}\right)
$$

over all $x \in G_{t}$ and all $p(m)$-tuples $\left\{\xi_{\alpha}:|\alpha|=m\right\}$ of real numbers, it is clear that $E(t)$ cannot decrease as $t$ decreases, so that $\lim _{\inf _{t \rightarrow 0+}} E(t)>0$. Moreover, since $B$ is bounded and continuous on $\bar{G}_{t}$, there exists $r$ such that $\lim \inf _{t \rightarrow 0+} b(t)>r>-\infty$. Hence $\lim _{t \rightarrow 0+} \lambda_{0}(t)=+\infty$.

The author (Ph. D. Thesis, University of British Columbia) has applied a form of this theorem (in the cases where $G_{t}$ is an annulus or a finite cylinder in $R^{n}$ ) in the derivation of oscillation theorems for elliptic differential equations of even order $2 m$. 


\section{REFERENCES}

1. S. Agmon, Lectures on elliptic boundary value problems, Van Nostrand, Princeton, 1965 .

2. R. Courant and D. Hilbert, Methods of mathematical physics, Vol. I, Interscience, New York, 1953.

3. I. M. Glazman, Direct methods of qualitative spectral analysis of singular differential operators, Israel Program for Scientific Translations, Daniel Davey and Co., New York, 1965.

4. V. B. Headley and C. A. Swanson, Oscillation criteria for elliptic equations, Pacific J. Math. 27 (1968), 501-506.

5. S. G. Mikhlin, The Problem of the minimum of a quadratic functional, Holden Day, San Francisco, 1965.

Received November 5, 1968.

BROCK UNIVERSITY,

St. Catharines, Ontario 


\section{PACIFIC JOURNAL OF MATHEMATICS}

\section{EDITORS}

H. ROYDEN

Stanford University

Stanford, California

\section{RichaRd PIERCE}

University of Washington Seattle, Washington 98105
J. DugundJI

Department of Mathematics

University of Southern California

Los Angeles, California 90007

BASIL GORDON

University of California

Los Angeles, California 90024

\section{ASSOCIATE EDITORS}
E. F. BECKENBACH
B. H. NeUMANN
F. WOLF
K. YOSHIDA

\section{SUPPORTING INSTITUTIONS}

UNIVERSITY OF BRITISH COLUMBIA CALIFORNIA INSTITUTE OF TECHNOLOGY

UNIVERSITY OF CALIFORNIA

MONTANA STATE UNIVERSITY

UNIVERSITY OF NEVADA

NEW MEXICO STATE UNIVERSITY

OREGON STATE UNIVERSITY

UNIVERSITY OF OREGON

OSAKA UNIVERSITY

UNIVERSITY OF SOUTHERN CALIFORNIA

\author{
STANFORD UNIVERSITY \\ UNIVERSITY OF TOKYO \\ UNIVERSITY OF UTAH \\ WASHINGTON STATE UNIVERSITY \\ UNIVERSITY OF WASHINGTON \\ AMERICAN MATHEMATICAL SOCIETY \\ CHEVRON RESEARCH CORPORATION \\ TRW SYSTEMS \\ NAVAL WEAPONS CENTER
}

The Supporting Institutions listed above contribute to the cost of publication of this Journal, but they are not owners or publishers and have no responsibility for its content or policies.

Mathematical papers intended for publication in the Pacific Journal of Mathematics should be in typed form or offset-reproduced, double spaced with large margins. Underline Greek letters in red, German in green, and script in blue. The first paragraph or two must be capable of being used separately as a synopsis of the entire paper. It should not contain references to the bibliography. Manuscripts, in duplicate if possible, may be sent to any one of the four editors. Please classify according to the scheme of Math. Rev. 36, 1539-1546. All other communications to the editors should be addressed to the managing editor, Richard Arens, University of California, Los Angeles, California, 90024.

50 reprints are provided free for each article; additional copies may be obtained at cost in multiples of 50 .

The Pacific Journal of Mathematics is published monthly. Effective with Volume 16 the price per volume (3 numbers) is $\$ 8.00$; single issues, $\$ 3.00$. Special price for current issues to individual faculty members of supporting institutions and to individual members of the American Mathematical Society: $\$ 4.00$ per volume; single issues $\$ 1.50$. Back numbers are available.

Subscriptions, orders for back numbers, and changes of address should be sent to Pacific Journal of Mathematics, 103 Highland Boulevard, Berkeley, California, 94708.

PUBLISHED BY PACIFIC JOURNAL OF MATHEMATICS, A NON-PROFIT CORPORATION

Printed at Kokusai Bunken Insatsusha (International Academic Printing Co., Ltd.), 7-17. Fujimi 2-chome, Chiyoda-ku, Tokyo, Japan. 


\section{Pacific Journal of Mathematics}

\section{Vol. 30, No. $3 \quad$ November, 1969}

Willard Ellis Baxter, Topological rings with property $(Y) \ldots \ldots \ldots \ldots . \ldots 5$

Sterling K. Berberian, Note on some spectral inequalities of $C . R$.

Putnam ..................................... 573

David Theodore Brown, Galois theory for Banach algebras . ........... 577

Dennis K. Burke and R. A. Stoltenberg, A note on p-spaces and Moore spaces ........................................ 601

Rafael Van Severen Chacon and Stephen Allan McGrath, Estimates of positive contractions....................................... 609

Rene Felix Dennemeyer, Conjugate surfaces for multiple integral problems in the calculus of variations ........................... 621

Edwin O. Elliott, Measures on countable product spaces.............. 639

John Moss Grover, Covering groups of groups of Lie type .............. 645

Charles Lemuel Hagopian, Concerning semi-local-connectedness and cutting in nonlocally connected continua .................. 657

Velmer B. Headley, A monotonicity principle for eigenvalues ........... 663

John Joseph Hutchinson, Intrinsic extensions of rings . . . . . . . . . . . . . 669

Harold H. Johnson, Determination of hyperbolicity by partial

prolongations .................................. 679

Tilla Weinstein, Holomorphic quadratic differentials on surfaces in $E^{3} \ldots 697$

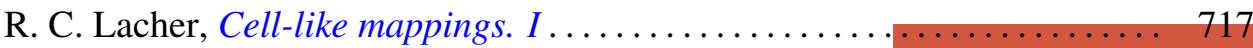

Roger McCann, A classification of centers

Curtis L. Outlaw, Mean value iteration of nonexpansive mappings in a

Banach space...

Allan C. Peterson, Distribution of zeros of solutions of a fourth order

differential equation.

Bhalchandra B. Phadke, Polyhedron inequality and strict convexity .. 765 Jack Wyndall Rogers Jr., On universal tree-like continua .

Edgar Andrews Rutter, Two characterizations of quasi-Frobenius rings

G. Sankaranarayanan and C. Suyambulingom, Some renewal theorems concerning a sequence of correlated random variables...

Joel E. Schneider, A note on the theory of primes........ . .

Richard Peter Stanley, Zero square rings .................

Edward D. Tymchatyn, The 2-cell as a partially ordered space

Craig A. Wood, On general Z.P.I.-rings................ 